\title{
ASPECTOS FONOAUDIOLÓGICOS NA SÍNDROME DE CROUZON: ESTUDO DE CASO
}

\section{Speech-language aspects on Crouzon syndrome: case study}

\author{
Isabela Gomes ${ }^{(1)}$, Suelly Cecília Olivan Limongi (2), Ivone Ferreira Neves ${ }^{(3)}$, \\ Maria Inês Vieira Couto ${ }^{(4)}$, Carla Gentile Matas ${ }^{(5)}$
}

\section{RESUMO}

Tema: descrever os aspectos fonoaudiológicos de um caso de Síndrome de Crouzon, com idade de 6:4 anos, submetendo-o às avaliações das áreas de fala, linguagem, cognição, sistema estomatognático e audição. Procedimentos: o sujeito foi submetido às seguintes avaliações: ABFW, Prova de Vocabulário Receptivo, Avaliação do Desenvolvimento de Linguagem-Cognição, Avaliação de Estruturas e Funções do Sistema Estomatognático, Audiometria Tonal Limiar, Imitanciometria e Logoaudiometria. Resultados: a Audiometria Tonal identificou perda auditiva condutiva de grau moderado bilateralmente, apresentando compatibilidade com a Logoaudiometria e a Imitanciometria. A Avaliação de Sistema Estomatognático indicou tônus de estruturas diminuído, com postura e mobilidade alteradas. As funções de sucção, mastigação, deglutição e respiração mostraram-se alteradas. $\mathrm{Na}$ avaliação da Fonologia, identificaram-se simplificação do encontro consonantal, plosivação de fricativa e outros. Em Fluência, os dados estavam abaixo do esperado para a mesma faixa etária e sexo. Na prova de Pragmática o número de atos por minuto foi 14,4, apresentando como meio comunicativo predominante o gestual. Na prova de Vocabulário Receptivo, o valor total de designações usuais estava 7,1\% abaixo do valor de referência. No Vocabulário Expressivo, os dados apontaram para referência entre 4 e 5 anos, abaixo dos parâmetros esperados para a idade do sujeito do estudo. Em Linguagem e Cognição, as análises indicaram defasagem em relação à fase de desenvolvimento. Conclusão: os comprometimentos causados pela síndrome são difusos e interligados, tendo a importância desse estudo apresentar os aspectos fonoaudiológicos de um caso de Síndrome de Crouzon e fornecer dados para aprofundar a investigação fonoaudiológica e o processo terapêutico.

DESCRITORES: Craniossinostose; Linguagem Infantil; Cognição; Sistema Estomatognático; Audição

(1) Fonoaudióloga; Bolsista FAPESP de Capacitação Técnica; Especialista em Linguagem pela Faculdade de Medicina da Universidade de São Paulo.

(2) Fonoaudióloga; Professora Associada do Departamento de Fisioterapia, Fonoaudiologia e Terapia Ocupacional da Faculdade de Medicina da Universidade de São Paulo; Livre-Docente do Curso de Fonoaudiologia da Faculdade de Medicina da Universidade de São Paulo.

(3) Fonoaudióloga Técnica de nível superior do Departamento de Fisioterapia, Fonoaudiologia e Terapia Ocupacional da Faculdade de Medicina da Universidade de São Paulo; Doutora em Ciências pela Faculdade de Medicina da Universidade de São Paulo.

(4) Fonoaudióloga Técnica de nível superior do Departamento de Fisioterapia, Fonoaudiologia e Terapia Ocupacional da Faculdade de Medicina da Universidade de São Paulo; Doutora em Ciências pela Faculdade de Medicina da Universidade de São Paulo.

(5) Fonoaudióloga; Professora Doutora do Departamento de Fisioterapia, Fonoaudiologia e Terapia Ocupacional da Faculdade de Medicina da Universidade de São Paulo.

\section{INTRODUÇÃO}

A craniossinostose é a alteração craniana congênita mais comum em humanos, caracterizada pelo fechamento prematuro das suturas cranianas. Mais de 100 síndromes estão associadas a este tipo de deformidade, sendo a maioria com padrão de herança genética autossômica dominante, com incidência, em geral, de 0,4 a 1 para cada mil nativivos ${ }^{1}$. Os quadros clínicos mais comumente encontrados reportam-se às Síndromes de Saethre-Chotzen, Apert, Crouzon e Pfeiffer ${ }^{1}$. Os fatores ambientais, assim como os genéticos, podem contribuir para o surgimento da craniossinostose ${ }^{2}$. São citados cinco genes que, quando alterados, podem causar essa modificação no crescimento craniano: GFR1, FGFR2, FGFR3, TWIST e MSX2. Em estudo 
recente, foi possível identificar outra mutação, considerando-se o gene FGFR3 ${ }^{3}$.

As sinostoses são classificadas de acordo com as suturas cranianas fechadas precocemente e a quantidade destas. A mais comum é a escafocefalia (sinônimo de dolicocefalia) ${ }^{4-6}$. A craniossinostose torna o crânio uma caixa rígida, impedindo a expansão cerebral. Conseqüentemente, desenvolvem-se aumento da pressão intracraniana, compressão do cerebelo e/ou do nervo óptico, podendo acarretar em progressiva herniação e/ou perda de visão ${ }^{7}$. Entretanto, alguns autores apontam a controvérsia existente com relação às anormalidades presentes serem determinadas primaria ou secundariamente às alterações ósseas ${ }^{8}$. Os autores apontam que a previsão de prognóstico pode apresenta melhores respostas em indivíduos cuja sinostose é de origem primária.

Uma das mais freqüentes craniossinostoses, caracterizada por sinostose craniana, hipertelorismo, exoftalmia, nariz de "formato de bico de papagaio", má formação dos condutos auditivos, lábios superiores curtos, palato duro alto e estreito, podendo apresentar fissura palatina, hipoplasia maxilar e relativo prognatismo mandibular, apinhamento dentário, sendo a má formação craniana dependente da velocidade e da ordem da sinostose, é denominada Síndrome de Crouzon e foi descrita por Crouzon em $1912{ }^{6}$. O diagnóstico da síndrome é baseado nos sinais clínicos ${ }^{6}$, além da descrição da presença de defazagem cognitiva ${ }^{9}$, e confirmado com os resultados dos testes de DNA, tendo o lócus do gene no braço longo do cromossomo 10 , região 26 (10q26) ${ }^{10}$.

Questões fonoaudiológicas na síndrome de Crouzon foram estudadas em um paciente ${ }^{10} \mathrm{a}$ partir da aplicação do ITPA (Teste Illinois de Habilidades Psicoloingüísticas) e relatados: alterações como comprometimento nas habilidades sintáticas, semânticas, fonológicas e pragmáticas; prejuízo nos canais relacionados com os processos de linguagem (auditivo e visual); a avaliação psicológica apontou para a presença de deficiência mental moderada. Mas, os autores obtiveram dados que indicaram compreensão oral para palavras e sentenças simples e semi-complexas preservada.

Estudos audiológicos ${ }^{11,12}$ apontam para achados como alterações de orelha externa ou média e perdas auditivas condutiva, neurossensorial ou mista. Foram encontrados, também, indivíduos que apresentavamcondições dentrodanormalidade ${ }^{12}$. Apesar dos poucos relatos sobre achados audiológicos ${ }^{11,12}$, na literatura encontra-se eco à necessidade de estudos e maior preparo de profissionais da área da otorrinolaringologia que lidarão, diretamente, com a população que apresenta patologias advindas de quadros sindrômicos ${ }^{13}$.

Considerando tais dados apresentados, este trabalho tem como objetivo realizar um estudo de caso, obtendo dados de fala e linguagem (fonologia, vocabulário, fluência e pragmática), de audição, de sistema estomatognático e de cognição de um sujeito do sexo feminino com o diagnóstico de Síndrome de Crouzon, correlacionando os achados individuais com os descritos na literatura.

\section{APRESENTAÇÃO DO CASO}

C.D.P.C. é a $2^{\mathrm{a}}$ filha de casal com dados de desenvolvimento normais, não consangüíneo e sem histórico familiar para Síndrome de Crouzon. Realizou, aos quarenta e cinco dias de vida, craniotomia descompressiva e quatorze dias após esta cirurgia recebeu entubação orotraqueal prolongada, sendo submetida a uma traqueostomia, com a qual permanece atualmente. Nos testes moleculares realizados identificou-se a presença da mutação C342S, confirmando o diagnóstico da síndrome. Entre os anos 2000 e 2002 realizou cirurgias de correção da cranioestenose, avanço em monobloco para colocação de distrator externo, reposicionamento do distrator e retirada do distrator. Em laringotraqueobroncoscopia realizada, concluiu-se que possuía hipertrofia severa de adenóide, responsável pela obstrução significativa do fluxo aéreo nas coanas, estando em seguimento clínico na área desde então. Em 2005 iniciou o tratamento fonoaudiológico no LIF-SASM.

Foram realizadas, anteriormente ao início do processo terapêutico fonoaudiológico, avaliações nas áreas de fala e linguagem, audição, sistema estomatognático e cognição de um sujeito do gênero feminino de seis anos e quatro meses, atendido semanalmente no LIF-SASM (Laboratório de Investigação Fonoaudiológica em Síndromes e Alterações Sensório-Motoras) do Departamento de Fisioterapia, Fonoaudiologia e Terapia Ocupacional da Faculdade de Medicina da Universidade de São Paulo, onde foi desenvolvido o estudo.

O sujeito da pesquisa foi submetido primeiramente a avaliações audiológicas, com a utilização de otoscópio marca Heine, audiômetro GSI 10, 61 ou 68 (Grason - Stadler) e imitanciômetro GSI 33 (Grason - Stadler).

O sistema estomatognático foi avaliado quanto à morfologia, tonicidade, mobilidade e responsividade de suas estruturas, além das funções de alimentação ${ }^{14}$.

Avaliou-se fala e linguagem por meio do ABFW Teste de Linguagem 15, aplicado na íntegra, obtendo-se dados sobre fonologia, vocabulário (também denominado de "vocabulário expressivo"), 
pragmática e fluência. Foi utilizada a Prova de Vocabulário Receptivo ${ }^{16}$, com a apresentação de pranchas de figuras separadas por categorias semânticas, nas quais devem ser identificadas as figuras representativas de palavras-alvo.

A Avaliação de Linguagem e Cognição foi realizada em situação de brincadeira espontânea, utilizando-se material específico para esta avaliação e seguindo a metodologia adotada pelo LIF-SASM 17-19.

Esse estudo foi aprovado pela Comissão de Ética para Análise de Projetos de Pesquisa (CAPPesq) da Diretoria Clínica do Hospital das Clínicas e da Faculdade de Medicina da Universidade de São Paulo (FMUSP) sob protocolo 078/03.

Todas as avaliações realizadas foram transcritas em protocolos específicos para posterior análise. A avaliação completa foi realizada em cinco dias, sendo um dia dedicado à avaliação audiológica com a duração aproximada de uma hora e quatro dias, em sessões de 45 minutos cada, para as demais avaliações. Após a conclusão do estudo, a devolutiva à família foi realizada em uma sessão.

\section{RESULTADOS}

A avaliação audiológica identificou perda auditiva condutiva de grau moderado. Os testes de fala foram compatíveis com os limiares auditivos para tons puros e a imitanciometria revelou curva timpanométrica tipo $B$ e ausência de reflexos estapedianos ipsilaterais em ambas as orelhas.

Foram observadas alterações de estruturas e funções do Sistema Estomatognático quanto à tonicidade para as estruturas moles e, especificamente com relação aos lábios e língua, quanto à mobilidade e à postura, entreabertos e no soalho da boca respectivamente; a responsividade apresentou-se aumentada. Palato duro e frênulos apresentaramse adequados. Quanto às estruturas duras, foi observado palato duro estreito e em ogiva, dentes em estado adequado de conservação, mas com apinhamento tanto em região anterior quanto posterior de arcadas, além de oclusão em classe III de Angle. As funções de alimentação apresentaram-se com inadequações: sucção com pouca protrusão labial e contração de bucinadores, força diminuída, mas com vedamento labial; mastigação com incisão dos alimentos adequada, mas sem manter oclusão labial e fraca contração dos músculos masseteres e temporais; deglutição com interposição lingual para todas as consistências e participação excessiva da musculatura perioral. A respiração era oral ou através da traqueostomia. Apesar dos achados relatados, o sujeito apresentou ritmo, coordenação e velocidade entre as funções e introdução de quan- tidade de alimento adequados, o que favoreceu a eficiência de sua realização.

Na prova de Imitação de Fonologia houve a produção de Simplificação do Encontro Consonantal (25\%), processo esperado para a idade, e na categoria Outros, verificou-se a presença de denasalização de sons plosivos. Na prova de Nomeação houve a produção de plosivação de fricativa $(4,5 \%)$, estando inadequada para a idade, e em Outros, observou-se denasalização de sons plosivos.

A prova do Vocabulário indicou designações abaixo do esperado para a faixa etária, exceto no campo semântico "Móveis e Utensílios", conforme demonstrado na Tabela 1. As não designações estavam acima do esperado em "Meios de Transporte", "Locais" e "Formas e Cores". Como se pode observar, os resultados apresentados na prova de Vocabulário aproximaram-se dos valores de referência de indivíduos de faixa etária entre 4.0 e 5.0 anos ${ }^{15}$.

Na Tabela 2 são apresentados os valores médios para as faixas etárias de 4.0, 5.0 e 6.0 anos para a Prova de Vocabulário Receptivo e os valores obtidos pelo sujeito, tendo como referências as palavras-alvo. O valor total de designações, conforme pode ser verificado, está $7,59 \%$ abaixo do valor de referência para a idade ${ }^{16}$.

Ao se realizar a análise dos valores obtidos pelo sujeito com relação às palavras alvo da prova de vocabulário receptivo e compará-los com os valores médios de 4.0, 5.0 e 6.0 anos por campo semântico podemos verificar que os campos "vestuário", "animais" e "meios de transporte" encontram-se abaixo do valor médio de 4.0 anos, que os campos "alimentos", "locais", "formas e cores" e "brinquedos e instrumentos musicais" encontram-se entre os valores médios de 4.0 e 5.0 anos e "móveis e utensílios" e "profissões" encontram-se acima do valor de 6.0 anos, totalizando ambos $100 \%$ de acerto cada. O total de acertos refere-se a $81,39 \%$ o que ficaria entre os valores médios de 4.0 e 5.0 anos $(71,93 \%$ e $88,64 \%$ respectivamente).

Os dados obtidos nas provas de vocabulário receptivo e expressivo sugerem, então, localização do sujeito na mesma faixa etária, entre 4.0 e 5.0 anos, embora a comparação entre ambas as provas identifique melhores resultados para o vocabulário receptivo em todos os campos, com exceção de "meios de transporte".

Os dados do Perfil da Fluência são apresentados na Tabela 3, obtidos por meio da amostra de fala coletada, na qual são identificadas as Tipologias das Rupturas, a Velocidade de Fala e a Freqüência das Rupturas da fala do sujeito da pesquisa. Como se pode observar, todos os resultados 
Tabela 1 - Comparação entre os valores de referência para a Prova de Vocabulário Expressivo e os valores obtidos

\begin{tabular}{lccccccccccccc}
\hline \multirow{2}{*}{ Campo } & \multicolumn{4}{c}{ \%DVU } & \multicolumn{1}{c}{ \%ND } & \multicolumn{6}{c}{ \%PS } \\
\cline { 2 - 12 } & 4.0 & 5.0 & 6.0 & $\mathrm{R}$ & 4.0 & 5.0 & 6.0 & $\mathrm{R}$ & 4.0 & 5.0 & 6.0 & $\mathrm{R}$ \\
\hline Vestuário & 50 & 65 & 80 & 60 & 10 & 5 & 0 & 0 & 40 & 30 & 20 & 40 \\
Animais & 40 & 60 & 70 & 46,6 & 20 & 15 & 20 & 6,6 & 40 & 25 & 10 & 46,6 \\
Alimentos & 60 & 70 & 90 & 73,3 & 20 & 15 & 5 & 0 & 20 & 15 & 5 & 26,6 \\
Meios de & 50 & 60 & 70 & 63,6 & 5 & 0 & 5 & 18,2 & 45 & 40 & 25 & 18,2 \\
$\begin{array}{l}\text { Transp. } \\
\text { Móveis e }\end{array}$ & 60 & 60 & 65 & 70,8 & 5 & 5 & 5 & 4,1 & 35 & 35 & 30 & 25 \\
Utensílios & 20 & 35 & 45 & 40 & 40 & 25 & 25 & 0 & 40 & 40 & 30 & 60 \\
$\begin{array}{l}\text { Profissões } \\
\text { Locais }\end{array}$ & 50 & 70 & 70 & 16,6 & 25 & 10 & 5 & 41,6 & 25 & 20 & 25 & 33,3 \\
$\begin{array}{l}\text { Formas e } \\
\text { Cores }\end{array}$ & 30 & 70 & 85 & 60 & 10 & 10 & 5 & 10 & 60 & 20 & 10 & 30 \\
Brinq. e & & & & & & & & & & & & \\
Instrum. & 40 & 55 & 70 & 54,5 & 20 & 10 & 10 & 9,7 & 40 & 35 & 20 & 36,3 \\
Musicais & & & & & & & & & & & & \\
\hline
\end{tabular}

DVU: Designação Verbal Usual; ND: Não designação; OS: Processo de Substituição; 4.0 - Valores de referência de normalidade para a idade de 4.0 anos; 5.0 - Valores de referência de normalidade para a idade de 5.0 anos; 6.0 - Valores de referência de normalidade para a idade de 6.0 anos; $R$ - Valor obtido pela resposta do sujeito

Tabela 2 - Comparação entre os valores de referência de designação verbal usual da prova de Vocabulário Receptivo para 4.0, 5.0 e 6.0 anos e o valor obtido pelo sujeito

\begin{tabular}{lcccc}
\hline \multirow{2}{*}{ Campo } & \multicolumn{3}{c}{ \%DVU } \\
\cline { 2 - 5 } & 4.0 & 5.0 & 6.0 & $\mathrm{R}$ \\
\hline Vestuário & 78,75 & 93,75 & 91,25 & 75 \\
Animais & 85 & 97,5 & 95,83 & 83,3 \\
Alimentos & 77,5 & 92,5 & 95 & 83,3 \\
Meios de Transporte & 58,75 & 85 & 80 & 50 \\
Móveis e Utensílios & 87,5 & 94,37 & 95 & 100 \\
Profissões & 51,25 & 71,25 & 67,5 & 100 \\
Locais & 53,75 & 80 & 81,25 & 75 \\
Formas e Cores & 62,5 & 93,75 & 95 & 75 \\
Brinquedos e Instrumentos & 67,5 & 77,5 & 87,5 & 75 \\
Musicais & & & & 81,39 \\
Total & 71,93 & 88,64 & 88,98 & \\
\hline
\end{tabular}

DVU: Designação Verbal Usual; 4.0 - Valores de referência de normalidade para a idade de 4.0 anos; 5.0 - Valores de referência de normalidade para a idade de 5.0 anos; 6.0 - Valores de referência de normalidade para a idade de 6.0 anos; $R$ - Resposta obtida pelo sujeito

demonstrados estão abaixo dos valores de referência para faixa etária e sexo.

$\mathrm{Na}$ Tabela 4 constam os dados da prova da Pragmática. O número total de atos comunicativos foi 144 , sendo 14,4 atos por minuto. O número mínimo de atos comunicativos em indivíduos de aproximadamente sessenta meses refere-se a 8 atos por minuto e de noventa meses a 9 atos por minuto, o que indica que o sujeito da pesquisa encontra-se acima do valor da sua faixa etária ${ }^{15}$. As três funções comunicativas predominantes foram: Jogo (20,13\%), Comentário (18,05\%) e Pedido de Ação (14,58\%).

Na Figura 1 são apresentados os resultados das análises quantitativo/qualitativa referentes à avaliação de linguagem e cognição, a partir do jogo simbólico e do uso de frases, uma vez que as aquisições anteriores já estavam estabelecidas. Com relação 
Tabela 3 - Valores referentes à prova de Fluência

\begin{tabular}{|c|c|c|c|}
\hline \multicolumn{2}{|c|}{ Disfluências comuns } & \multicolumn{2}{|c|}{ Disfluências gagas } \\
\hline hesitações & 3 & rep. sílabas & 0 \\
\hline interjeições & 0 & rep. sons & 0 \\
\hline revisões & 0 & prolongamentos & 0 \\
\hline pal. não terminadas & 0 & bloqueios & 0 \\
\hline repetição de palavras & 1 & pausas & 0 \\
\hline repetição de segmentos & 1 & $\begin{array}{l}\text { intrusão de sons ou } \\
\text { segmentos }\end{array}$ & 0 \\
\hline repetição de frases & 1 & & \\
\hline TOTAL & $6\left(11,6-18,2^{*}\right)$ & TOTAL & $0\left(1,4-4,6^{\star}\right)$ \\
\hline \multicolumn{2}{|c|}{$\begin{array}{c}\text { Fluxo de palavras por minuto } \\
55,71\left(58,5-82,3^{\star}\right) \\
\end{array}$} & \multicolumn{2}{|c|}{$\begin{array}{c}\text { Fluxo de sílabas por minuto } \\
95,24\left(103,6-144,5^{\star}\right) \\
\end{array}$} \\
\hline \multicolumn{2}{|c|}{$\begin{array}{c}\% \text { de descontinuidade de fala } \\
3\left(7,1-10,9^{*}\right)\end{array}$} & \multicolumn{2}{|c|}{$\begin{array}{c}\% \text { de disfluências gagas } \\
0\left(0,7-2,3^{*}\right)\end{array}$} \\
\hline
\end{tabular}

* Valores de referência da normalidade para a faixa etária de 6.0 a 6.11 e sexo feminino.

Tabela 4 - Valores Referentes à prova de Pragmática

\begin{tabular}{ccc}
\hline Meio & № & $\%$ \\
\hline Verbal & 65 & 45,2 \\
Vocal & 5 & 3,4 \\
Gestual & 74 & 51,3 \\
\hline TOTAL & 144 & $100 \%$ \\
\hline
\end{tabular}

ao desenvolvimento cognitivo, o sujeito apresentava jogo simbólico com combinação de esquemas simbólicos e por imitação exata do real, além de ter a noção de conteúdo-continente estabelecida, realizar a classificação por semelhança ou por diferença, realizar a seriação e a dupla relação por experimentação, fazer a correspondência termo-a-termo, obedecendo o critério de tamanho e apresentar a antecipação e o planejamento de ações para situações compostas por ações seqüenciadas. Com relação à linguagem, fazia uso de frases justapostas por coordenação e subordinação que expressavam as noções cognitivas construídas.

\section{DISCUSSÃO}

Os dados da Avaliação Audiológica indicaram perda auditiva condutiva de grau moderado, confirmada pelos Testes de Fala e pela Imitanciometria. Estes dados corroboram pesquisa anterior ${ }^{11}$, que caracterizaram o quadro audiológico da síndrome de Crouzon com uma grande variedade de altera- ções, entre elas as de orelha média e as perdas auditivas ${ }^{12}$.

Verifica-se que as alterações de Sistema Estomatognático não podem ser analisadas como dados isolados e sim como decorrentes do crescimento craniano comprometido. Em pesquisa com 11 sujeitos com síndrome de Crouzon ${ }^{20}$, identificou-se que os principais sinais clínicos encontrados foram disoclusão dentária, prognatia, palato em ogiva, hipoplasia da face média e exorbitismo, dados estes também encontrados no sujeito desta pesquisa. A mesioclusão encontrada no sujeito desta pesquisa pode ser atribuída não somente à displasia maxilar, mas também à excessiva altura do ramo mandibular e do ângulo do osso.

Os processos fonológicos observados foram de ocorrência assistemática e podem estar associados à perda auditiva e/ou à ressonância comprometida pela alteração craniana e pela hipertrofia de adenóides. Em estudo desenvolvido anteriormente ${ }^{21}$, investigando os históricos de otite média e infecções de vias aéreas superiores em crianças com distúrbio fonológico, observou-se que $51,8 \%$ dos sujeitos apresentaram histórico de otite média e $55,5 \%$ de histórico de infecções de vias aéreas superiores e $33 \%$ apresentaram as duas ocorrências. Porém, não foram encontradas relações significantes entre estas ocorrências e a gravidade do distúrbio fonológico.

O desempenho do sujeito nas provas de vocabulário receptivo e expressivo permitiu compará-lo ao de uma criança na faixa etária entre 4.0 e 5.0 anos, apresentando-se aquém do esperado para 


\begin{tabular}{|c|c|c|c|c|c|}
\hline \multirow{2}{*}{ Noções cognitivas } & \multicolumn{4}{|c|}{ Pontuação } & \multirow{2}{*}{ TOTAL } \\
\hline & 0 & 1 & 2 & 3 & \\
\hline $\begin{array}{l}\text { Jogo simbólico } \\
\text { (Fase II) }\end{array}$ & não realiza & $\begin{array}{c}\text { realiza por } \\
\text { combinação } \\
\text { simbólica } \\
\text { ordenada }\end{array}$ & $\begin{array}{c}\text { realiza por } \\
\text { imitação exata } \\
\text { do real }\end{array}$ & $\begin{array}{c}\text { apresenta } \\
\text { simbolismo } \\
\text { coletivo }\end{array}$ & 2 \\
\hline conteúdo/ continente & não realiza & & & realiza & 3 \\
\hline classificação & não realiza & figurativa & $\begin{array}{c}\text { por } \\
\text { semelhança } \\
\text { ou diferença }\end{array}$ & $\begin{array}{c}\text { por } \\
\text { semelhança e } \\
\text { diferença }\end{array}$ & 2 \\
\hline seriação/dupla relação & não realiza & aleatória & $\begin{array}{c}\text { por } \\
\text { experimentaçã } \\
0 \\
\end{array}$ & $\begin{array}{c}\text { por } \\
\text { comparação }\end{array}$ & 2 \\
\hline correspondência & não realiza & realiza & $\begin{array}{l}\text { com relação } \\
\text { de tamanho }\end{array}$ & $\begin{array}{l}\text { observa falta } \\
\text { ou sobra de } \\
\text { elementos }\end{array}$ & 2 \\
\hline $\begin{array}{c}\text { antecipação/ } \\
\text { planejamento de } \\
\text { ações }\end{array}$ & não realiza & uso do objeto & em seqüência & $\begin{array}{l}\text { uso de } \\
\text { relações }\end{array}$ & 2 \\
\hline \multicolumn{6}{|l|}{ Linguagem } \\
\hline uso de frases & não realiza & $\begin{array}{l}\text { combinação } \\
\text { de duas } \\
\text { palavras }\end{array}$ & $\begin{array}{l}\text { uso de frases } \\
\text { simples } \\
(S+V+O)\end{array}$ & $\begin{array}{l}\text { uso de frases } \\
\text { complexas } \\
\text { (coordenadas } \\
\text { e/ou } \\
\text { subordinadas) }\end{array}$ & 3 \\
\hline
\end{tabular}

Figura 1 - Análise quantitativo/qualitativa da avaliação linguagem/cognição

sua idade. A análise mais detalhada da prova de vocabulário expressivo do sujeito do presente estudo indicou que o processo de substituição mais utilizado foi o co-hipônimo próximo, que correspondeu a $34,14 \%$ dos processos utilizados. Esse dado indica que o sujeito consegue acessar o campo semântico corretamente, como também por seus semelhantes, mas não utiliza a designação da forma esperada ${ }^{22}$.

O número de disfluências comuns e gagas, o fluxo de sílabas e palavras por minuto e a taxa de descontinuidade de fala e de disfluências gagas estão abaixo do parâmetro de normalidade para a mesma faixa etária e sexo do sujeito ${ }^{15}$. Tais dados sugerem fala monótona e velocidade articulatória e taxa de produção da informação reduzidas.

Em indivíduos com Alteração de Desenvolvimento de Linguagem ${ }^{23}$, concluiu-se que a fluência reduzida que apresentam pode ser conseqüência do maior uso de gestos e do vocabulário defasado. Em outro estudo ${ }^{24} \mathrm{com}$ indivíduos com desenvolvimento típico de linguagem identificou-se que há correlação entre velocidade de fala e as tarefas de fluência semântica, concluindo-se que essa velocidade depende da eficácia de recuperação lexical, fator este que no sujeito apresentado neste artigo apresenta-se defasado, conforme demonstrado. Especificamente com relação à fluência, a literatura não relata achados relacionados à síndrome em estudo, mas os dados obtidos com relação à avaliação realizada traduzem a observação feita durante as sessões terapêuticas quanto às características de velocidade e produção de fala do sujeito.

Conforme pode ser constatado na prova de Pragmática, o meio comunicativo predominante é o gestual, seguido pelo verbal e vocal. O número mínimo de atos comunicativos indica que o sujeito da pesquisa encontra-se acima do valor da sua faixa etária ${ }^{15}$. Porém, uma das funções comunicativas mais freqüentes foi o jogo, o que indica que este tenha correlação com o meio comunicativo mais predominantemente gestual e pouco interativo.

A pragmática estuda a relação entre significado social da linguagem e o seu conteúdo semântico, sendo os transtornos desse aspecto comumente relacionados a prejuízos nos componentes expressivos e receptivos de linguagem ${ }^{25}$, o que se pode correlacionar com o desempenho abaixo do esperado nas provas de vocabulário e a forma predominantemente gestual, conforme observado nos resultados. Além disso, mostra-se importante a analise qualitativa neste caso, pois somente a 
análise quantitativa, que apresentou números acima do esperado para a faixa etária do sujeito, com relação ao número de atos comunicativos, não forneceria os dados reais das habilidades pragmáticas, como já foi demonstrado em estudo realizado anteriormente com indivíduos com e sem distúrbio específico de linguagem ${ }^{25}$.

Os dados apresentados e discutidos com relação às habilidades semântica, fonológica e pragmática do sujeito avaliado encontram respaldo na literatura em relato de estudo de caso ${ }^{10}$.

A literatura ${ }^{10}$ aponta a presença de defasagem cognitiva na síndrome de Crouzon, mas referindo a áreas funcionais como cuidados pessoais, habilidades acadêmicas funcionais, além de ócio e trabalho. Não foram encontrados dados que qualificassem tal defasagem. A avaliação realizada no presente estudo voltada para as áreas de cognição e linguagem ${ }^{17,18}$ está baseada nos princípios propostos pela Epistemologia Genética. A análise desses dados e sua avaliação qualitativa permitiram identificar as aquisições construídas pelo sujeito, o que favoreceu localizá-lo no período pré-operatório de seu desenvolvimento cognitivo, com realizações esperadas para a faixa etária de 5.0 anos. O mesmo pode ser observado com relação à linguagem expressiva, considerando-se, também, produção lexical ${ }^{15}$. Infelizmente, os dados observados nessas áreas, para o sujeito do presente estudo, não encontram eco na literatura. Como referido anteriormente, são escassos os relatos sobre achados lingüísticos na síndrome de Crouzon ${ }^{10}$.

\section{CONCLUSÃO}

O comprometimento causado pela Síndrome de Crouzon é difuso e pode apresentar outros achados que não são os comumente descritos, como pode ser observado neste estudo de caso.

Portanto, é necessário realizar avaliações amplas e que apresentem maior variedade de análises e dados que possam ser comparados entre si e com as descrições da síndrome.

\section{ABSTRACT}

Background: to describe the results of speech, language, cognition, stomatognathic system and hearing assessments of a case of Crouzon syndrome at the age 6:4 years. Procedure: the subject carried out the following evaluations: ABFW, Test of Receptive Vocabulary, LanguageCognition Development Evaluation, Evaluation of Structures and Functions of the Stomatognathic System, pure-tone audiometry threshold, immitance measures and vocal audiometry. Results: the pure-tone audiometry identified bilateral moderate conductive hearing loss, compatible with vocal audiometry's and immitance measures' results. The stomatognathic system evaluation showed that the structures had reduced tonus and altered posture and mobility. Suction, chewing, deglutition and breathing functions were also altered. Phonologically, the following processes were identified: Cluster Simplification, Stopping of Fricatives and Others. In the Fluency evaluation, subject's performance was below the expected scores for matched age and gender. In the Pragmatics test, the child had 14.4 acts per minute and, predominantly, gestural communication. The Receptive Vocabulary Test showed scores $7.1 \%$ below reference. In the Expressive Vocabulary Test, data indicated a performance compatible to the reference values of 4 and 5 year-old children, below the expected scores for the subject's age. Regarding language and cognition, the analysis indicated a gap between the child's performance and the developmental level. Conclusion: the deficits caused by the syndrome are diffuse and interconnected. The present study had the aim to present the Speech-Language and Hearing Pathology associated aspects of a Crouzon syndrome case and to provide initial data to further investigate these aspects and the intervention process.

KEYWORDS: Craniosynostoses; Child Language; Cognition; Stomatognatic System; Hearing

\section{REFERÊNCIAS}

1. Arduino-Meirelles AP, Lacerda CBF, Gil-da-SilvaLopes VL. Aspectos sobre desenvolvimento de linguagem oral em craniossinostoses sindrômicas. Pró-Fono. 2006; 18(2):213-20.
2. Passos-Bueno MR, Jehee FS, Armelin LML. Aspectos moleculares das craniossinostoses: implicações no diagnóstico e aconselhamento genético. Rev Med. 2001; 80(1):7-13.

3. Arnoud-Lopez L, Fragoso R, Mantilla-Capacho J, Barros-Núñez P. Crouzon with acanthosis nigricans. 
Further delineation of the syndrome. Clin Genet. 2007; 72(5):405-10.

4. Alonso LG. Estudo genético-clínico das craniossinostoses genéticas e associadas [mestrado]. São Paulo (SP): Universidade Federal de São Paulo; 1997.

5. Cohen MMJr, Gorlin RJ, Fraser FC. Craniofacial disorders. In: Rimoin DL, Connor JM, Pyeritz RE. Emery and Rimoin's principles and practice of medical genetics. 3. ed. New York: Churchill Livingston; 1997.

6. Carinci F, Pezzetti F, Locci P, Beccetti E, Carls F, Avantaggiato $A$ et al. Apert and Crouzon Syndromes: clinical findings, genes and extracellular matrix. $J$ Craniofac Surg. 2005; 16(3):361-8.

7. Hoefkens MF, Vermeji-Keers C, Vaandrager JM. Crouzon syndrome: phenotypic signs and symptoms of the postnatally expressed subtype. J Craniofac Surg. 2004; 15(2):233-40.

8. Raybaud C, Di Rocco C. Brain malformation in syndromic craniosynostoses, a primary disorder of white matter: a review. Child Nerv Syst. 2007; 23(12):1379-88.

9. Okkerse JM, Beemer FA, Mellenbergh GJ, Wolters WH, Heineman-de Boer JA. Risk factors for visual-motor integration and intelligence in children with craniofacial anormalies. J Craniof Surg. 2005; 16(4):517-24.

10. Milanez SGC, Abramides DVM, Fernandes AY, Giacheti CM. Síndrome de crouzon: avaliação fonoaudiológica e desempenho no ITPA. Rev Soc Bras Fonoaudiol. Supl Esp. 2004.

11. Orvidas LJ, Fabry LB, Diacova S, McDonald TJ. Hearing and otopathology in Crouzon syndrome. Laryngoscope. 1999; 109(9):1372-5.

12. Corey JP, Caldarelli DD, Gould HJ. Otopathology in cranial facial dysostosis. Am J Otol. 1987; 8(1):14-7.

13. Malone KJ, Cook SS. Introduction to genetics otorhinolaryngology nurses. ORL Head Neck Nurs. 2006; 24(2):8-18.

\section{RECEBIDO EM: 30/10/2007 \\ ACEITO EM: 25/04/2008}

Endereço para correspondência:

Departamento de Fisioterapia, Fonoaudiologia e Terapia Ocupacional da Faculdade de Medicina da Universidade de São Paulo

Rua Cipotânea, 51

São Paulo - SP

CEP: $05360-000$

Tel: (11) 3091-8408

E-mail: fgaisagomes@yahoo.com.br
14. Val DC, Limongi SCO, Flabiano FC, Silva KCL. Sistema estomatognático e postura corporal na criança com alterações sensório-motoras. PróFono. 2005; 17(3):345-54.

15. Andrade CRF, Befi-Lopes, DM, Fernandes, FDM, Wertzner HF. ABFW - Teste de linguagem infantil nas áreas de fonologia, vocabulário, fluência e pragmática. 2. ed. Carapicuíba: Pró-Fono; 2005.

16. Morselli AA. Verificação da compreensão e produção lexical em crianças com desenvolvimento normal da linguagem e com alteração no desenvolvimento da linguagem [mestrado]. São Paulo (SP): Universidade de São Paulo; 2003.

17. Limongi SCO, Carvallo RMM, Souza ER. Auditory processing and language in Down syndrome. J Medical Speech-Lang Pathol. 2000; 8(1):27-34.

18. Pires SCF. A relação linguagem-cognição no trabalho com Comunicação Suplementar e/ou Alternativa com a criança com paralisia cerebral. [mestrado]. São Paulo (SP): Universidade de São Paulo; 2005.

19. Flabiano FC, Buhler KECB, Limongi SCO, Mendes AE. Quantitative and qualitative assesment on language and cognition in toddlers. Proceedings of Annual Convention of the American SpeechLanguage Hearing Association; 2006 Nov; Miami, USA.

20. Yacubian-Fernandes A, Ducati LG, Silva MV, Abramides DVM, Perosa GB, Palhares A, et al. Síndrome de Crouzon: fatores envolvidos no desenvolvimento neuropsicológico e na qualidade de vida. Arq Neuro-Psiquiatr. 2007; 65(2b):467-71. 21. Wertzner HF, Rosal CAR, Pagan LO. Ocorrência de otite média e infecções de vias aéreas superiores em crianças com distúrbio fonológico. Rev Bras Fonoaudiol. 2002; 7(1):31-7.

22. Rocha LC, Befi-Lopes DM. Análise pragmática de crianças com e sem distúrbio específico de linguagem. Pró-Fono. 2006; 18(3):229-38.

23. Befi-Lopes DM, Araújo K. Velocidade de fala em crianças com alteração no desenvolvimento de linguagem. Rev Bras Fonoaudiol. 2002; 7(1):55-61. 24. Martins IP, Vieira R, Loureiro C, Santos ME. Speech rate and fluency in children and adolescents. Child Neuropsychol. 2007; 13(4):319-32.

25. Befi-Lopes DM, Puglisi ML, Rodrigues A, Giusti E, Gândara JP, Araújo K. Perfil comunicativo de crianças com alterações específicas no desenvolvimento da linguagem: caracterização longitudinal das habilidades pragmáticas. Rev Soc Bras Fonoaudiol. 2007; 12(4):265-73 